\title{
Non-randomized Trial of POGIL for Improving Undergraduates' Academic Achievement in Science Education
}

\author{
David Agwu Udu*, Nmadu Saba John, Chidebe Chijioke Uwaleke, \\ Okechineke Benjamin Chukwunonso, Anudu Adaora Phina, Precious Chisom Attamah
}

Department of Science Education, Faculty of Education, Alex Ekwueme Federal University, Ndufu-Alike, Nigeria

Received May 20, 2020; Revised June 30, 2020; Accepted July 20, 2020

\section{Cite This Paper in the following Citation Styles}

(a): [1] David Agwu Udu, Nmadu Saba John, Chidebe Chijioke Uwaleke, Okechineke Benjamin Chukwunonso, Anudu Adaora Phina, Precious Chisom Attamah, "Non-randomized Trial of POGIL for Improving Undergraduates' Academic Achievement in Science Education," Universal Journal of Educational Research, Vol. 8, No. 9, pp. 4019 - 4027, 2020. DOI: 10.13189/ujer.2020.080927.

(b): David Agwu Udu, Nmadu Saba John, Chidebe Chijioke Uwaleke, Okechineke Benjamin Chukwunonso, Anudu Adaora Phina, Precious Chisom Attamah (2020). Non-randomized Trial of POGIL for Improving Undergraduates' Academic Achievement in Science Education. Universal Journal of Educational Research, 8(9), 4019 - 4027. DOI: 10.13189/ujer.2020.080927.

Copyright $\bigcirc 2020$ by authors, all rights reserved. Authors agree that this article remains permanently open access under the terms of the Creative Commons Attribution License 4.0 International License

\begin{abstract}
This study investigated the effectiveness of process-oriented guided-inquiry learning (POGIL) pedagogy in improving male and female undergraduates' academic achievement in science education, in comparison with the conventional lecture method. A non-equivalent, control group quasi-experimental design was used to investigate male and female undergraduates' achievement in science education. Data were collected from 85 second-year science education undergraduates and analyzed using mean, standard deviation, and analysis of covariance. The results show that POGIL pedagogy, as opposed to lecture pedagogy, resulted in improved academic achievement in science education $\left(\mathrm{F}_{(1,82)}=26.66\right.$, $\mathrm{P}=.000,<.05)$. The data provided evidence to suggest that undergraduates that learned by the POGIL method had a greater grasp of content knowledge than their counterpart that learned by the lecture approach, as evidenced by higher mean achievement scores for POGIL undergraduates. There was no significant influence of gender on the undergraduates' achievement in the POGIL $\left(\mathrm{F}_{(1,37)}=.805, \mathrm{P}=.375,>.05\right)$. The findings of the study have implications for the restructuring of science education teaching environments in the university system by de-emphasizing and discouraging the use of teacher-centered pedagogies and promoting the use of the
\end{abstract}

current student-centered pedagogies for enhancing the undergraduates' academic achievement. The researchers, therefore, recommend that lecturers should organize science educational environments to support active learning strategies for improved undergraduates' academic achievement in science education.

Keywords Improved Academic Achievement, Non-randomized Trial, POGIL, Science Education, Undergraduates

\section{Introduction}

Science education involves understanding how students learn science, how best teachers can teach, and how to improve learning outcomes by changing teaching strategies, including appropriate training of science instructors. Nwagbo opined that all students need certain levels of scientific knowledge and related skills, especially at the university level of education, to contribute meaningfully in the development of society [1]. However, research studies have shown that students seem not to be acquiring these scientific skills and literacy from universities. This 
has partly been attributed to the perceived abstract nature of science concepts by students. This might be connected to the fact that to understand scientific concepts, students need to possess good imagery abilities since most scientific concepts/phenomena are not visible [2,3]. But the acquisition of good imagery abilities by students may be achieved when the instructors use student-centered instructional practices that encourage students' interaction and active participation in the learning processes [4]. Despite the importance of active learning strategies, instructors continue to primarily use teacher-centered methods such as lectures with little text reading and student discourse, which is partially rooted in the teacher's belief that the best way to ensure content learning is for the instructor to present all necessary information to students [5]. But research evidence has shown that conventional teaching strategies such as the lecture method do not enable all students to appropriately engage with the types of academic literacy constitutive to higher education [6].

Meanwhile, several studies conducted on the assessment of students' understanding of scientific concepts, have shown that a large number of students experience misconceptions about science concepts, which results in their overall poor academic performance in science, technology, engineering and mathematics (STEM) education in general $[1,7,8]$. In the effort to improve students' understanding of science concepts and a resultant improvement on their academic performance in science, researchers have suggested that science teachers at all levels of education should first identify the students' misconceptions and then employ effective teaching strategies that will engage the students actively to remediate the misconceptions $[8,9,10,11,12,13,14]$.

From the foregoing, it is evident that effective science teaching and learning can be achieved when teachers show commitment to the progress of students by creating supportive environments that take care of the students' differences. Lecturers can achieve this by utilizing effective active learning strategies that give students the opportunity for cooperative and collaborative work, and allow them to engage in sustained conversation and hands-on activities. There are several approaches to active learning strategies that have proved to be effective in enhancing students' academic achievement. These include Peer Instruction, Active Learning Problem Sets, Constructivist Classroom Dialogue, Demonstration Strategies, Cooperative Learning Strategies, etc. However, this study evaluates the effectiveness of the Process Oriented Guided Inquiry Learning (POGIL) strategy.

Process-oriented guided-inquiry learning (POGIL) instructional strategy is a research-based student-centered pedagogy employed to teach science courses in small groups and to engage students to use materials through guided inquiry. It is a constructivist learning approach [15]. Similarly, Hein sees POGIL as a student-centered learning method in which student teams discover content to assemble concepts in the classroom, with the teacher acting as the facilitator [16]. Continuing, Hein stated further that in the POGIL strategy, students work on activities in groups to explore concepts, to develop their mental constructs which they can later apply to problem-solving. This will enable them to develop problem-solving and subsequently, higher-order thinking skills.

Contributing, Warfa described POGIL as a small group, lecture-free instructional strategy with two distinct components: process skills and guided inquiry [17]. Warfa [17] further emphasized that the process skills component of POGIL includes: communication, teamwork, problem-solving, critical thinking, group management, information processing, and self-assessment skills. These skills are facilitated by assigning particular roles to each member of the group such as manager, reflector, and presenter. On the other hand, the guided inquiry component of POGIL follows a three-phase learning process, which is: the exploration phase - in which the students develop the desired content from the model they are provided with; the concept development phase - in which the students learn new terminologies and links between their prior knowledge and the new concepts developed; and the application phase - in which the students demonstrate the utilization of the new concepts developed by applying them to new situations. All these processes could enhance the students' grasp of content knowledge thereby improving their academic achievement in the subject area.

Meanwhile, Hanson noted that in the POGIL structure, the teacher performs the role of a facilitator of learning. The teacher does not directly intervene in any of the group's discussions and activities unless his attention is needed by any of the groups for direction and clarification purposes [18]. The facilitator encourages the students to construct knowledge rather than providing answers for them. In his analysis, Hanson [18] emphasized that when the facilitator regularly provides answers, the students learn to wait passively for information instead of constructing concepts and principles themselves. This, Hanson noted will defeat the objectives of the use of the POGIL strategy. The facilitators are therefore required to guard against this practice.

Furthermore, it is expedient that all the students should be actively involved in the learning activities and should also participate actively in the various tasks through continuous alternate role-playing within the groups. Moreover, a facilitator should ensure that no student or group of students monopolizes the activities in the learning cycles. These can be achieved when the facilitator effectively monitors the groups' activities and intervenes only when there are genuine needs to do so.

The review of other related literature shows that students who are taught with the POGIL instructional strategy always record significant improvement in their mean academic achievement scores more than their counterparts 
taught with conventional strategies such as the lecture method. These studies show that all innovative teaching strategies which are activity-oriented and student-centered are more effective in building enduring understandings of difficult science topics than conventional, teacher-centered pedagogy such as the lecture method $[9,15,16,19,20,21,22$, 23]. Specifically, Roller and Zori found that the use of POGIL resulted in a significantly better acquisition of concepts in nursing science [22]. Similarly, Hein found that students taught using the POGIL method had better organic chemistry examination results than those who were taught through traditional teaching methods [16].

Moreover, a study conducted by Vanags, Pammer, and Brinker found that the students taught with POGIL showed a drastic increase in their academic performance at the end of the course which positively helped them to improve their academic confidence, more than their counterparts taught using lecture method [23]. Meanwhile, Hanson reported that college students taught using POGIL in general chemistry had a significant increase in their academic performances. The students further wrote that they wished they had been taught using POGIL methods in high schools [18].

Furthermore, the positive effects of the POGIL active learning strategy were further validated by Lorenzo, Crouch, and Mazur, that the use of active learning strategies in science teaching not only yielded a significant increase in male and female students' academic achievement but also reduced the gender gap in academic achievement [24]. More importantly, they also found that male and female students who were taught science subjects using the active learning instructional strategies had no significant difference in their mean academic achievement scores. They concluded that there was no significant influence of gender on the students' achievement when taught with active learning strategies such as the POGIL. Similarly, Lewis and Lewis reported that students who were taught using active learning, student-centered, and Peer-Led Guided Inquiry (PLGI) performed better than their counterparts, who were taught with lecture method [21]. Moreover, Bahar and Aksüt opined that activity-based science teaching strategies affect children's problem-solving skills positively, thereby enhancing their academic achievement [25].

From the foregoing, it can be established that POGIL and other active learning pedagogies are effective in improving students' academic achievement in science courses. These are supported by the plethora of research reviewed above which suggests that active learning strategies awaken varieties of internal developmental processes that can operate effectively when the learner is actively participating in the teaching and learning processes by interacting with peers and materials within the educational environment. Meanwhile, the relevant literature reviewed has shown that most evaluations of the POGIL strategy have been in the discipline of chemistry, with few studies conducted in biology, physics, mathematics, engineering, nursing science, anatomy, and physiology. However, the researchers are yet to identify literature in science education. Hence, this study is justified.

\subsection{Purpose of the Study}

The main purpose of this study is to investigate the use of process-oriented guided inquiry learning (POGIL) for improving undergraduates' academic achievement in science education. Specifically, the study investigates:

1. the effectiveness of POGIL over the conventional lecture method in improving undergraduates' academic achievement in science education.

2. the influence of gender on the undergraduates' academic achievement in science education when taught with POGIL.

\subsection{Research Questions}

The following research questions guided the study:

1. Is the POGIL more effective than the conventional lecture method in improving undergraduates' academic achievement in science education?

2. What is the influence of gender on the undergraduates' academic achievement in science education course when taught with POGIL?

\subsection{Hypotheses}

The following null hypotheses were tested at .05 level of significance:

$\mathrm{H}_{01}$ : There is no significant difference in the effectiveness of POGIL and the conventional lecture method in improving undergraduates' academic achievement in science education.

$\mathrm{H}_{02}$ : There is no significant influence of gender on the undergraduates' academic achievement in science education when taught with POGIL.

\section{Materials and Methods}

\subsection{Research Design and Participants}

The study utilized a quasi-experimental design. Specifically, the pre-test, post-test, non-equivalent, and non-randomized control group design. The pre-test was first administered to the experimental and control groups after which the experimental groups were exposed to POGIL instructions, while the control groups were taught with the conventional (lecture) instructions, at the end of which the post-test was administered to both the experimental and the control groups. The duration of the study was five weeks. 
The study was carried out in one of the federal universities in the south-eastern part of Nigeria. The study was specifically conducted in the department of science education in the faculty of education at the university. The course used for the study was SED 216 (Introduction to Science Education). The course as described in the university handbook is a second-semester general course for all the second-year students of the four (4) programs in the department of science education. The four (4) programs are biology education, chemistry education, mathematics education, and physics education, with class sizes of 34,31 , 9, and 11 students respectively in the 2018/2019 academic session. The programs were randomly assigned to experimental groups (chemistry and mathematics education), and control groups (biology and physics education). The groups were taught using the same course contents, but with different instructional strategies.

The population of the study was eighty-five (85) undergraduates (37 males and 48 females). The entire population was used for the study because it was a manageable size, hence there was no sample. The experimental groups consisted of forty (40) undergraduates (18 males and 22 females), while the control groups comprised forty-five (45) undergraduates (19 males and 26 females). The undergraduates' ages ranged from 19 to 21 years old, with an average age of 20 years. The students in both the experimental and control groups had similar socioeconomic status (SES), with the majority of them coming from middle to upper-class socioeconomic status families. The experimental and control groups were taught by the researchers. This helped to prevent the treatment diffusion factor, which would have affected the validity of the study.

\subsection{Data Collection Tools and Analysis}

The instruments used in this study were science education achievement test (SEAT) and process-oriented guided inquiry learning manual (POGILM). The instruments were developed by the researchers. The SEAT consists of fourteen (14) restricted response essay test items, which was developed to test the undergraduates' ability to state definitions, explain concepts, show relationships between concepts and use the concepts to solve problems. The administration of the science education achievement test took 50 minutes. The SEAT was made up of open-ended, essay-type questions and problems, to which marks were allotted according to the weight of the questions. The SEAT was based on a 50-point scale. The researchers used the open-ended essay test rather than multiple-choice test items to check the undergraduates' level of conceptual understanding of science education and their ability to organize thoughts logically. All the questions were prepared from the course contents as contained in the POGILM.

The POGIL manual contained a total of five (5) POGIL activities that were prepared from the topics in the course contents, including justification and limitations of science and technology; the impact of science on man and society and world politics; the impact of society on science and technology; cultural implications of science and technology; and justification of science in primary and secondary schools' curriculum. The instruments were face and content validated by two experts in the department of science education of the university. The items were revised based on the experts' suggestions. The reliability of the SEAT was established through a pilot study conducted on 30 undergraduates of the science education department of another university and the results were analyzed with Kuder-Richardson's formula $20\left(\mathrm{~K}-\mathrm{R}_{20}\right)$ with a reliability index of .84 which showed that it was internally consistent. The pre-SEAT was also used as the post-SEAT, but the questions in the post-SEAT were renumbered to seem different at face value.

\subsection{Experimental Procedure}

The experimental and control groups were taught for 2 hours weekly for the 5 weeks. The experimental groups were exposed to POGIL while the lecture groups were taught using the conventional lecture method. The experimental groups were arranged in small groups. There was a total of 8 groups, and each group was made up of 5 members. Each of the groups was given the POGIL manual which contained designed activities on the bases of the three-phase structure of the learning cycle: the exploration phase; the concept invention phase and the application phase. The groups were heterogeneously formed to reflect a fair mix of male and female undergraduates. All the undergraduates in the experimental groups were assigned to specific roles (manager, presenter, recorder, and reflector). They took turns in playing these roles for each activity as contained in the POGIL manual. They also followed the rules of sharing their views among themselves while responding to critical thinking questions in particular and prepared group files containing the works and the answers they provided to the critical questions. They were told to respond only to the critical thinking questions included in the activities. After each activity, individual members of each group were evaluated and marks awarded to them. The sum of individual group members' scores makes up the groups' marks. The group with the highest mark receives a prize from the facilitator.

The facilitators in the experimental groups were monitoring the progress of the undergraduates as they carried out the exercises and were checking on their activities to ensure that they followed the laid down procedures. The facilitators also intervened at the invitation of any group that required some clarifications from the materials. Inter-group interactions were also encouraged but monitored by the facilitators to avoid degenerating into rowdy sessions. After each exercise, the facilitator 
collapsed the groups and evaluated the learning outcome on individual students. The scores of individual students were recorded against their groups to make up the groups' points.

On the other hand, in the control groups, the undergraduates were taught using conventional lecture methods in the form of lecture notes and questioning. The method was characterized by explanations, discussions, and the use of textbooks. The researchers structured the lecture environment and the whole learning process in which the students were required to take notes, while the lecturers explain the concepts using the whiteboard. The lecturers' questions were responded to by the undergraduates by way of verbalization.

Meanwhile, all other activities in the experimental and control groups were similar except the use of POGIL activities in the experimental group but were replaced with note-taking and verbal responses to questions in the lecture group.

\subsection{Data Analysis}

The data collected were analyzed using an appropriate data analysis program, statistical package for social sciences (SPSS) version 23. Firstly, the Mann-Whitney U test was used to analyze and determine the differences among the pre-test mean scores of the experimental and control groups. This was done to determine the balance of the experimental and control groups before the implementation of the experiment. Meanwhile, the research questions were answered using mean and standard deviation, while Analysis of Covariance (ANCOVA) was used to test the null hypotheses. The ANCOVA helped to eliminate the errors of non-equivalence arising from non-randomization of the research subjects, thereby correcting the error of initial differences, if any, in the ability levels among the research subjects.

\subsection{Limitations of the Study}

The research was conducted at one science education department in a federal university in a suburban setting. The study which was conducted in a variety of programs including Biology Education, Chemistry Education, Physics Education, and Mathematics Education programs might yield different results. Moreover, the researchers could not control for such variables as learning styles of students, the students' study habits and how they achieve mastery of the subject content as well as the teaching styles of the lecturers involved in the study and these could have influenced the final grades achieved by the undergraduates in the study.

\section{Results and Discussion}

The results of this study are as presented below. The data obtained from the administration of the SEAT to the experimental and control groups were analyzed accordingly.

\subsection{Determining the Compatibility in Ability Levels of Experimental and Control Groups}

The researchers first determined the compatibility of the experimental and control groups' initial ability levels by determining the differences in their pre-test scores using the Mann-Whitney U test statistics as shown in Tables 1 below.

Table 1 shows the Mann-Whitney U test to compare the initial ability levels of the experimental and control groups using the pre-test scores. The table shows that there was no statistically significant difference in the mean pre-test scores of the experimental and control groups $(\mathrm{U}=854.5$, $\mathrm{p}$ $=.686,>.05)$. From the results in Table 1 , it can be deduced that the undergraduates in the experimental and control groups had similar academic achievement abilities at the beginning of the experiment. This similarity is essential to demonstrate the effectiveness of the teaching strategies. This was further emphasized by Kaplan in [25] who opined that in an ideal experimental study, pre-test scores for experimental and control groups should be as close as possible.

Table 1. Mann-Whitney U test for the difference between experimental and control groups pre-test scores

\begin{tabular}{|c|c|c|c|c|c|c|c|}
\hline Group & $\mathbf{N}$ & $\begin{array}{l}\text { Mean } \\
\text { Rank }\end{array}$ & $\begin{array}{l}\text { Sum of } \\
\text { Ranks }\end{array}$ & Mann-Whitney U & Wilcoxon W & $\mathbf{Z}$ & $\begin{array}{c}\text { Asymp. Sig } \\
\text { (2-tailed) }\end{array}$ \\
\hline $\begin{array}{l}\text { Experimental } \\
\text { (POGIL) }\end{array}$ & 40 & 44.14 & 1765.50 & \multirow{2}{*}{854.50} & \multirow{2}{*}{1889.50} & \multirow{2}{*}{-.405} & \multirow{2}{*}{.686} \\
\hline $\begin{array}{l}\text { Control } \\
\text { (Lecture) }\end{array}$ & 45 & 41.99 & 1889.50 & & & & \\
\hline
\end{tabular}




\subsection{Effectiveness of POGIL over Conventional Lecture method in Improving Undergraduates' Academic Achievement (Research question 1 and Hypothesis 1)}

Table 2. Mean Achievement Scores and Standard deviation of Undergraduates taught with POGIL and Lecture method

\begin{tabular}{lccl}
\hline \multicolumn{1}{c}{ Group } & Mean & SD & N \\
\hline Experimental (POGIL) & 34.90 & 5.022 & 40 \\
Control (Lecture) & 30.18 & 5.006 & 45 \\
Total & 32.40 & 5.519 & 85 \\
\hline
\end{tabular}

Table 2 above shows that the mean academic achievement score with the standard deviation of the experimental group taught science education with POGIL was 34.90 and 5.02 respectively. On the other hand, the mean achievement score with the standard deviation of the control group taught with lecture method was 30.18 and 5.01 , respectively. The table shows a difference of 4.72 in the mean achievement scores of the two groups, with the POGIL group having a higher mean score than the Lecture group. However, the table did not show whether the observed difference in the mean achievement scores of the two groups was statistically significant or otherwise. Hence, the inferential testing of the null hypothesis 1 as hereunder shown in Table 3.

Table 3 shows a one-way analysis of covariance which compared the effectiveness of two instructional strategies (POGIL and Lecture method) while controlling for the pre-test effect. The table 3 shows a statistically significant difference between the mean achievement scores of the experimental and control groups $\left(F_{(1,82)}=26.66, P=.000\right.$, $<.05$ and $\eta_{\mathrm{p}}{ }^{2}=.25$ ). Therefore, the null hypothesis 1 , of no significant difference in the effectiveness of the POGIL and lecture method in improving the undergraduates' academic achievement in science education was rejected at .05 alpha level. This shows that the earlier observed difference in the mean academic achievement scores of the undergraduates taught with POGIL and Lecture method in Table 2, was significant. This implies that the POGIL strategy was more effective in improving the undergraduates' academic achievement than the Lecture method. Also, the partial Eta squared value of .25 obtained shows the effect size, which is considered small when compared with Cohen's guidelines (.2 - small effect, .5 moderate effect, .8 - large effect). This indicates that $25 \%$ of the variance in the undergraduates' achievement test scores explained by the independent variable (treatment) was fair. The results of this study have shown that, generally, the undergraduates' learning outcomes in science education can be considerably improved through the use of process-oriented guided-inquiry learning in the teaching and learning processes. These findings give credence to the results of past research studies on active learning such as those of $[16,22,23,25]$ that the process-oriented guided-inquiry learning improves students' learning outcomes more than the conventional lecture method. This could have been a result of the collaborative and cooperative manner in which the undergraduates studied using the POGIL strategy.

Moreover, by collaboratively and cooperatively engaging in active learning activities through the POGIL strategy, learners tend to be conscious of the fact that their success or failure depends upon their ability to work together as a team in their different groups, thereby necessitating their resolve to encourage and help one another to solve the critical thinking questions and other activities contained in the POGIL for their groups to succeed. In the POGIL, the learners are encouraged to feel free to interact with their group members and request for the facilitators' intervention when necessary. Furthermore, the prize attachment to the best group might have served as a motivating factor for the members of the groups to work harmoniously to achieve their goal. Hence, the groups shun competition among the members, rather they encouraged each other by working together and helping one another to learn meaningfully and for each member to score very high marks for the group to emerge victoriously. This might have contributed to the overall effectiveness of the POGIL strategy in improving the undergraduates' academic achievement in science education over the lecture method.

Table 3. Summary of One-way Analysis of Covariance Result on Mean Achievement Scores of Undergraduates taught with POGIL and Lecture method

Tests of Between-Subjects Effects

\begin{tabular}{ccccccc}
\hline Dependent Variable: & \multicolumn{2}{l}{ Post-test } & & & & \\
\hline Source & Type III Sum of Squares & Df & Mean Square & F & Sig. & Partial Eta Squared \\
\hline Corrected Model & $1259.230^{\mathrm{a}}$ & 2 & 629.615 & 39.740 & .000 & .492 \\
\hline Intercept & 3305.117 & 1 & 3305.117 & 208.610 & .000 & .718 \\
\hline Pre-test & 787.007 & 1 & 787.007 & 49.674 & .000 & .377 \\
\hline Method & 422.373 & 1 & 422.373 & 26.659 & .000 & .245 \\
\hline Error & 1299.170 & 82 & 15.844 & & & \\
\hline Total & 91788.000 & 85 & & & & \\
\hline Corrected Total & 2558.400 & 84 & & & &
\end{tabular}

a. R Squared $=.492($ Adjusted R Squared $=.480)$ 


\subsection{Influence of Gender on Undergraduates' Academic Achievement in Science Education (Research question 2 and Hypothesis 2)}

Table 4. Mean Achievement Scores and Standard deviation of Male and Female Undergraduates taught with POGIL

\begin{tabular}{cccc}
\hline Gender & Mean & SD & N \\
\hline Male & 36.24 & 5.044 & 17 \\
Female & 33.91 & 4.880 & 23 \\
Total & 34.90 & 5.022 & 40 \\
\hline
\end{tabular}

Table 4 shows mean and standard deviation scores of male and female undergraduates taught science education courses with POGIL. The table shows that the mean achievement score with the standard deviation of the male undergraduates was 36.24 and 5.04 respectively. Similarly, the mean achievement score with the standard deviation of the female undergraduates was 33.91 and 4.88 respectively. This result shows a difference of 2.33 in the mean achievement scores of the male and female undergraduates with the males scoring higher. This shows that the male undergraduates had slightly higher mean achievement scores than their female counterparts. However, it could not be established from the table, whether the observed difference was statistically significant or can be attributed to sampling error. Hence, the inferential testing of the null hypothesis 2 as shown in table 5 below.

Table 5 shows the summary of a one-way analysis of covariance conducted to test the influence of gender on undergraduates' academic achievement when taught with the POGIL instructional strategy. The result shows no significant difference in the mean achievement scores of the male and female undergraduates $\left(F_{(1,37)}=.805, P\right.$ $=.375,>.05$ ). Therefore, the null hypothesis 2 , of no significant influence of gender on the academic achievement of the undergraduates taught with POGIL was not rejected at .05 alpha level. This implies that the difference in the mean academic achievement scores of the male and female undergraduates taught with POGIL as earlier observed in Table 4 was not statistically significant which means that the undergraduates' gender did not significantly influence their academic achievement in the science education course statistically. This finding agrees with the findings of previous research studies that gender has no significant influence on the students' academic achievement in science subjects when teachers utilize active learning strategies such as, the POGIL, that encourage collaboration, cooperation, and communication among the learners by creating activities that decrease competitiveness $[24,26,27,28]$. Moreover, by creating a classroom environment that benefits both male and female undergraduates, the process-oriented guided-inquiry instructional approach investigated in this study would improve both male and female undergraduates' academic achievement in science education, without undue influence of gender.

Table 5. Summary of One-way Analysis of Covariance of Undergraduates’ Mean Academic Achievement Scores by Gender

\begin{tabular}{ccccccc}
\hline \multicolumn{7}{c}{ Tests of Between-Subjects Effects } \\
\hline Dependent Variable: & \multicolumn{2}{c}{ Post-test } & & & & \\
\hline Source & Type III Sum of Squares & df & Mean Square & F & Sig. & Partial Eta Squared \\
\hline Corrected Model & $600.749^{\text {a }}$ & 2 & 300.375 & 29.029 & .000 & .611 \\
\hline Intercept & 1426.213 & 1 & 1426.213 & 137.834 & .000 & .788 \\
\hline Pre-test & 548.034 & 1 & 548.034 & 52.964 & .000 & .589 \\
\hline Gender & 8.332 & 1 & 8.332 & .805 & .375 & .021 \\
\hline Error & 382.851 & 37 & 10.347 & & & \\
\hline Total & 49704.000 & 40 & & & & \\
\hline Corrected Total & 983.600 & 39 & & & & \\
\hline
\end{tabular}

a. R Squared $=.611($ Adjusted R Squared $=.590)$ 


\section{Conclusions and Recommendations}

This study investigated the effectiveness of process-oriented guided-inquiry learning (POGIL) in improving male and female undergraduates' academic achievement in science education, in comparison with the conventional lecture method. The study established that the POGIL pedagogy was more effective than the conventional lecture method in improving the undergraduates' academic achievement in science education. The finding of this study suggests that the use of process-oriented guided-inquiry learning by the lecturers should be prioritized over the conventional lecture method. This is on the backdrop that the POGIL activities applied in this research effectively improved the undergraduates' academic achievement in science education. With this positive result obtained from POGIL, the university authorities and other stakeholders should encourage the development and use of active learning strategies, specifically the process-oriented guided-inquiry learning by the university lecturers. The lecturers should also organize their educational environments to support active learning, thereby improving the undergraduates' academic achievement in science education by engaging actively in science activities. Furthermore, this study has supported the fact that undergraduates' academic achievement can be effectively improved when the lecturers utilize process-oriented guided-inquiry learning and other active learning strategies in their science educational environments.

The study further proved that the POGIL strategy improved the undergraduates' understanding of conceptual knowledge and the potential for the development of critical thinking and creative abilities. These research findings have implications for how science education should be restructured in the university system to incite dissatisfaction in the present teacher-centered pedagogies and align the lecturers' thinking with the current student-centered pedagogies which will restructure the science educational environments. The implication is the development of interest in science education by the undergraduates which will translate to an improved standard of science education in general.

Based on the findings of this study, the researchers recommend that the science education lecturers and science teachers, in general, should design, develop and utilize POGIL instructional pedagogy which is effective in improving undergraduates' academic achievement in science education more than the conventional lecture method. Also, the curriculum developers at all levels of education should develop a science education curriculum that will take into consideration the use of active learning strategies such as the POGIL in delivering science instructions in the classrooms. Moreover, further research should be conducted to determine the effect of POGIL on students' academic retention in science education and other courses that have larger class sizes.

\section{REFERENCES}

[1] Nwagbo, C. (2006). Effects of two teaching methods on the achievement in and attitude to the biology of students of different levels of scientific literacy. International Journal of Educational Research, 45(2006): 216-229. DOI:10.1016/j.ijer.2006.11.004

[2] Cook, E., Kennedy, E. \& McGuire, S. Y. (2013). Effect of teaching metacognitive learning strategies on performance in general chemistry courses. Journal of Chemical Education, 90(8): 961-967. DOI:10.1021/ed300686h

[3] Hofstein, A., Eilks, I. \& Bybee, R. (2011). Societal issues and their importance for contemporary science education: A pedagogical justification and the state of the art in Israel, Germany, and the USA. International Journal of Science and Mathematics Education, 9: 1459-1483. DOI:10.1007/s 10763-010-9273-9

[4] Shanahan, T. \& Shanahan, C. (2012) What is disciplinary literacy and why does it matter? Topics in Language Disorders 32(1): 7-18. DOI: 10.1097/TLD.0b013e3182445 $57 \mathrm{a}$

[5] Swanson, E., McCulley, L. V., Osman, D. J., Scammacca-Lewis, N. \& Solis, M. (2017). The effect of team-based learning on content knowledge: A meta-analysis. Active Learning in Higher Education, 20(1):39-50. DOI:10.1177/1469787417731201

[6] Hake, R.R., (1998). Interactive-engagement versus traditional methods: A six-thousand-student survey of mechanics tests data for an introductory physics course. American Journal of Physics, 66: 64-74.

[7] Anthony, C., Pakhira, D. \& Stains, M. (2013). Implementing process-oriented, guided-inquiry learning for the first time: Adaptations and short-term impacts on students' attitude and performance. Journal of Chemical Education, 90(4):409416. DOI:10.1021/ed300181t

[8] Partanen, L. (2016). Student-oriented approaches in the teaching of thermodynamics at universities - Developing an effective course structure. Chemistry Education Research and Practice, 17: 766-787. DOI:10.1039/c6rp00049e

[9] Barthlow, M. J. \& Watson, S. B. (2014). The effectiveness of process-oriented guided inquiry learning to reduce alternative conceptions in secondary chemistry. School Science and Mathematics, 114(5): 246-255. DOI:10.1111/ssm.12076

[10] Cepni, S. Tas, E. \& Kose, S. (2006). The effects of computer-assisted material on students' cognitive levels, misconceptions, and attitudes towards science. Computers \& Education, 46(2): 192-205.

DOI:10.1016/j.compedu.2004.07.008

[11] Dincer, S. \& Doganay, A. (2017). The effects of multiple-pedagogical agents on learners' academic success, motivation, and cognitive load. Computers \& Education, 111:74-100. DOI:10.1016/j.compedu.2017.04.005

[12] Jose, S., Patrick, P. G. \& Moseley, C. (2017). Experiential learning theory: the importance of outdoor classrooms in 
environmental education. International Journal of Science Education, Part B, 7(3): 269-284. DOI:10.1080/21548455. 2016.1272144

[13] Rahman, T., \& Lewis, S. E. (2019). Evaluating the evidence base for evidence-based instructional practices in chemistry through meta-analysis. Journal of Research in Science Teaching. DOI:10.1002/tea.21610

[14] Rokhmat, J., \& Putrie, S. D. (2019). A strategy of scaffolding development to increase students' problem-solving abilities: the case of physics learning with a causality-thinking approach. Journal of Turkish Science Education, 16(4): 569-579.

[15] Rosli, N. \& Mohd-Nasir, N. N. (2017). The use of the process-oriented guided inquiry learning (POGIL) approach to address form one students' misconceptions about weight and mass. In: Karpudewan M, Md Zain A. \& Chandrasegaran A (eds), Overcoming Students' Misconceptions in Science. Springer, Singapore. DOI:10.1007/978-981-10-3437-4_13.

[16] Hein, S. M. (2012). Positive impacts of using POGIL in organic chemistry. Journal of Chemical Education, 89: 860 864. DOI:10.1021/ed100217v

[17] Warfa, A. R. M. (2016). Using cooperative learning to teach chemistry: A meta-analytic review. Journal of Chemical Education, 93: 248-255.

DOI:10.1021/acs.jchemed.5b00608

[18] Hanson, D. M. (2013). Instructor's guide to process-oriented guided-inquiry learning. Hampton, NH: Pacific Crest.

[19] Brown, P. J. P. (2010). Process-oriented guided-inquiry learning in an introductory anatomy and physiology course with a diverse student population. Advances in Physiology Education, 34: 150-155. DOI:10.1152/advan.00055.2010

[20] Hanson, D. \& Wolfskill, T. (2000). Process workshops: A new model for instruction. Journal of Chemical Education,
77(1): 120-130. DOI:10.1021/ed077p120

[21] Lewis, S. E. \& Lewis, J. E. (2005). Departing from lectures: An evaluation of a peer-led guided inquiry alternative. Journal of Chemical Education, 82(1): 135-139. DOI:10.1021/ed082p135

[22] Roller, M. C. \& Zori, S. (2017). The impact of instituting Process-Oriented Guided-Inquiry Learning (POGIL) in a fundamental nursing course. Nurse Education Today, 50(1): 72-76. DOI:10.1016/j.nedt.2016.12.003

[23] Vanags, T., Pammer, K. \& Brinker, J. (2013). Process-oriented guided-inquiry learning improves long-term retention of information. Advances in Physiology Education. 37: 233-241. DOI:10.1152/advan.00104.2012

[24] Lorenzo, M., Crouch, C. H. \& Mazur, E. (2006). Reducing the gender gap in the physics classroom. American Journal of Physics. 74: 118-122. DOI:10.1119/1.2162549

[25] Bahar, M. \& Aksüt, P. (2020). Investigation on the Effects of Activity-Based Science Teaching Practices in the Acquisition of Problem-solving skills for 5-6 years old pre-school children. Journal of Turkish Science Education, 17(1), 22-39. DOI: 10.36681/tused.2020.11

[26] Brotman, J. S., \& Moore, F. M. (2008). Girls and science: A review of four themes in the science education literature. Journal of Research in Science Teaching, 45(9), 971-1002. DOI:10.1002/tea.20241

[27] Chen, C., Sonnert, G. \& Sadler, P. M. (2019). The effect of first high school science teacher's gender and gender matching on students' science identity in college. Science Education. 104(1), 75-99. DOI:10.1002/sce.21551

[28] Wang, M. T. \& Degol, J. L. (2017). Gender Gap in Science, Technology, Engineering, and Mathematics (STEM): Current Knowledge, Implications for Practice, Policy, and Future Directions. Educational Psychology Review, 29(1): 119-140. DOI:10.1007/s10648-015-9355-X 